\title{
Do erection-inducing drugs increase the incidence of sexually transmitted diseases among the elderly?
}

\author{
Ana Flávia Azevedo Querichelli1 \\ Bruna Eltz ${ }^{1}$ \\ Luís Cesar Fava Spessoto ${ }^{2}$ \\ (D) Fernando Nestor Facio Junior ${ }^{2}$
}

\begin{abstract}
1. Estudante de Graduação, Faculdade de Medicina de São José do Rio Preto (FAMERP), São José do Rio Preto, SP, Brasil 2 Departamento de Urologia, Faculdade de Medicina de São José do Rio Preto (FAMERP/FUNFARME), São José do Rio Preto, SP, Brasil
\end{abstract}

It is estimated that $22 \%$ of the world population will be 60 years old or older by the year $2050^{1}$. This increase in the population of seniors is attributed to improvements to sanitary conditions, changes in lifestyle (regular physical activity and adequate eating habits), and advances in medicine, including vaccines and antibiotics ${ }^{2}$.

Both the libido and desire to maintain sexual relations diminish with age due to the reduction in testosterone levels. Nonetheless, evidence suggests that despite a reduction in the frequency of sexual activity, older adults continue to have a sexual interest and/or be sexually active at an advanced age ${ }^{3}$. Although the rate of sexually transmitted diseases (STDs) is lower among seniors than younger individuals, the prevalence of some diseases, including HIV, has increased in this group ${ }^{3}$. Thus, this population is not free from the risk of STDs but should also not be deprived of sources of pleasures, health, and wellbeing ${ }^{4}$.

Epidemiological data show an increase in the incidence of STDs among seniors, especially those with low levels of schooling ${ }^{5}$. For example, the prevalence of acquired immunodeficiency syndrome (AIDS) increased from 7.5\% per 100,000 seniors in 1998 para $9.4 \%$ in $2010^{4}$. These data reflect an increase in the practice of unprotected sex in this population, which is the main transmission cause for STDs in all age groups ${ }^{5}$. This may be due to the fact that STD prevention campaigns are mainly directed at young peo$\mathrm{ple}^{5}$, and there is a reduction in the use of condoms with age ${ }^{6}$.

Reluctance to use condoms may be associated with a lack of awareness regarding the importance of the protection measure, embarrassment when purchasing the product, a lack of knowledge on how to use it, fear of not being able to maintain an erection, an erroneous notion that it only serves to avoid pregnancy, and a difficulty in negotiating non-use with one's partner ${ }^{4}$.

The advent of oral medications for the treatment of erectile dysfunction (ED), such as sildenafil (Viagra), which was approved in the 1990s, assisted middle-aged men and seniors in overcoming ED, which is highly prevalent in this population, affecting $40 \%$ of men between 57 and 85 years of age. Such medications 
have been prescribed to more than 16 million individuals worldwide since they first came onto the market ${ }^{6,7}$.

One study found an association between the use of sildenafil and an increase in risky sexual behavior ${ }^{6}$, reporting that users of this medication are twofold more likely to be diagnosed with HIV, and those who are HIV positive are more likely to be diagnosed with gonorrhea, chlamydia, or syphilis?.

As public health campaigns addressing SDTs are generally directed at the younger population, despite the growing evidence demonstrating that these diseases are a concern for patients of all ages ${ }^{3}$, educational programs should be implemented for health professionals, offering specific medical training for the needs of seniors ${ }^{3}$ and raising awareness regarding the use of condoms and its association with
STDs, especially when taking medication for erectile dysfunction.

\section{Conflicts of interest}

The authors declare there are no conflicts of interest associated with this publication.

\section{Author's contribution}

AFAQ, BE, LCFS, FNFJ - Substantial contributions to the conception or design of the work; or the acquisition, analysis, or interpretation of data for the work; drafting the work or revising it critically for important intellectual content; agreement to be accountable for all aspects of the work in ensuring that questions related to the accuracy or integrity of any part of the work are appropriately investigated and resolved; final approval.

\section{REFERENCES}

1. Kanasi E, Ayilavarapu S, Jones J. The aging population: demographics and the biology of aging. Periondotol 2000. 2016;72(6):13-8.

2. Lunenfeld B, Stratton P. The clinical consequences of an ageing world and preventive strategies. Best Pract Res Clin Obstet Gynaecol. 2013;27(5):643-59

3. Colton J. Sex and the elderly: what physicians should know about their older patients. Yale Med Thesis Digit Libr. 2008;317.

4. Brito NMI, Andrade SSC, Silva FMC, Fernandes MRCC, Brito KKG, Oliveira SHS. Idosos, infecções sexualmente transmissíveis e AIDS: conhecimentos e percepção de risco. ABCS Health Sci. 2016;41(3):140-5.

5. Silva BN, Sarmento WM, Silva FCV, Pereira MG, Silva CRDV, Véras GCB Panorama epidemiológico da AIDS em idosos. Hygeia - Rev Bras Geogr Médica Saúde. 2018;14(29):80-8.

6. Jena AB, Goldman DP, Kamdar A, Lakdawalla DN, Lu Y. Sexually transmitted diseases among users of erectile dysfunction drugs: analysis of claims data. Ann Intern Med. 2010;153(1):1-7.

7. Heudebert JP, Tamhane A, Burkholder GA, Dionne-Odom J. Erectile dysfunction medication prescription: STI and risk behavior in men with HIV. J Sex Med. 2019;16(5):691-700. 